\title{
Convergências entre as Humanidades Digitais e a Ciência da Informação: o uso das TICs em unidades de informação
}

\author{
Convergencia en las humanidades digitales y la ciencia de la información:
} el uso de las TIC en unidades de información

Convergences between the Digital Humanities and Information Science: the use of ICT in information units

\author{
leda Pelógia Martins Damian, Marco Antônio de Almeida, \\ Tayná Abad Vieira de MELlo, Paloma Barbosa RodRigues \\ FFCLRP-USP. Av. dos Bandeirantes, 3900, Ribeirão Preto, SP, Brasil \\ \{iedapm|marcoaa|tayna.mello|rpaloma.barbosa.rodrigues\}@usp.br
}

\begin{abstract}
Resumen
Tras reflexionar sobre el concepto de Humanidades Digitales y su conexión con la Ciencia de la Información desde una perspectiva interdisciplinaria, se muestran los resultados de un mapeo de experiencias concretas de acciones culturales o políticas desarrolladas en el contexto de las Humanidades Digitales en unidades de información del municipio de Ribeirão Preto, en el oeste de São Paulo (Brasil).

Palabras clave: Unidades de información. Tecnologías de la Información y la Comunicación. Usuarios. Humanidades digitales. Ciencias de la información. Ribeirão Prieto (Brasil).
\end{abstract}

\section{Introdução}

Diante da presença cada vez mais constante das Tecnologias de Informação e Comunicação (TICs) em todos os âmbitos da sociedade, o campo de atuação dos estudiosos das ciências ligadas à Comunicação, à Informação e à Documentação torna-se cada vez mais abrangente e diversificado. $\mathrm{O}$ estudo isolado dos documentos e processos técnicos já não é suficiente para promover o tratamento completo e correto das informações. É necessário que o profissional que lida com a informação, independente de seu formato, esteja ciente das implicações sociais que a mesma exerce na sociedade em diferentes contextos, e, inclusive, na relação que a sociedade mantém com os suportes informacionais disponíveis. Os conhecimentos relacionados ao fluxo informacional, as modificações no processo de comunicação e a adaptação dos métodos de documentação e organização intelectual precisam ser constantemente aprimorados, a fim de tal profissional manter-se sintonizado ao ritmo da pós modernidade em que nos encontramos.

\begin{abstract}
After discussing the concept of Digital Humanities and its connection with Information Science from an interdisciplinary perspective; results are presented of a survey of specific cultural and political actions carried on in the context of Digital Humanities in information units of Ribeirao Preto, a city in the west of São Paulo (Brazil).
\end{abstract}

Keywords: Information units. Information and communication technologies. Users. Digital Humanities. Informations science. Ribeirão Prieto (Brazil).

O incentivo ao avanço tecnológico, assim como o desenvolvimento contínuo de distintas formas de informação, assume importantes posições no estabelecimento de novos conjuntos de estruturas simbolicamente significantes e socialmente codificadas. Todas estas questões, devidamente ponderadas, levantam discussões sobre a abordagem cultural das tecnologias, fazendo parte de um processo de gerenciamento dos paradigmas corporativos - considerando o conjunto de seus componentes, sejam estes artefatos, conhecimentos, organizações, instituições ou símbolos. (Lévy, 1999) Desta maneira, a constante divulgação das informações pode nos levar a considerar a reestruturação dos modos de operação convencionais, e de todo um sistema de relações sociais.

O termo Humanidades Digitais, embora tenda a ser encarado como mais um rótulo generalista, surge como um campo interdisciplinar disposto a dar guarida às reflexões e às práticas suscitadas pelas mudanças decorrentes da introdução das tecnologias digitais nos universos da cultura e das Unidades de Informação. Assim, o surgimento das Humanidades Digitais aponta para a mudança do processo de comunicação como 
um todo. Nesse campo das Humanidades Digitais caberia distinguir vários territórios e enfoques, que variam dos mais pragmáticos aos mais teóricos (Svensson, 2010; Galina-Russell, 2011; Rodriguez Yunta 2013). Seu surgimento como campo de conhecimento e prática não é exclusividade do mundo anglo-saxão, embora seja nele que tenha se consolidado inicialmente (Svensson, 2010); por outro lado, começa a se consolidar também no mundo ibero-americano (Galina-Russell, 2011; Rodriguez Yunta 2013; Krebs, 2008). As convergências e afinidades entre as práticas e reflexões deste campo em relação à Ciência da Informação são evidentes, e estudos exploratórios visando a mapear possíveis pontes e intercruzamentos configuram-se como estratégicos na atual conjuntura.

O empenho em analisar a estrutura atual da produção, circulação acesso e apropriação dos bens culturais ainda não demonstrou convincentemente que a socialização do conhecimento ocorra. Assim, pretendemos com esse projeto participar dessa mudança do sistema de formação de quadros que corresponde às necessidades dessa mediação cultural, especialmente em museus digitais (Krebs, 2008; Roque, 2014a, 2014b). Do mesmo modo, o desafiador cenário globalizado não pode mais se dissociar do campo acadêmico das Humanidades Digitais, que transcendem a exclusiva preocupação com o uso de ferramentas informáticas aplicado às humanidades, configurando questões teóricas e/ou filosóficas próprias.

Ressalta-se que este trabalho faz parte de uma pesquisa de maior abrangência cujo resultado será a apresentação de um modelo para análise de Serviços de Referência Virtual.

\section{Humanidades Digitais em ação}

As Humanidades Digitais se configuram não só como objeto de pesquisas, mas também, cada vez mais, como um âmbito de ensino. Para Portela (2013), “(...)a ubiquidade da mediação digital em rede das últimas duas décadas criou um novo espaço de comunicação e de interação que afeta, por exemplo, as práticas de investigação e de ensino".

O estudo exploratório das Humanidades Digitais torna-se pertinente e estimulante para a área da Ciência da Informação, uma vez que é do interesse de ambas as áreas a aplicação de tecnologias que permitam a mediação e maior acessibilidade da informação. Ainda segundo Portella (2013):

(...) trata-se de usar as capacidades da tecnologia digital de um modo infletido que consiga incorporar categorias como a temporalidade, a historicidade e a subjetividade específica das representações e dos seus códigos próprios.

Guerrero \& Borbinha (2014) também reforçam essa ideia:

O alcance das humanidades digitais ultrapassa largamente a mera transferência do analógico para o meio digital, centrando-se no desafio epistemológico e na articulação com os conhecimentos e os métodos utilizados nas ciências humanas com o mundo digital.

O estudo acerca do uso dos recursos midiáticos na mediação de informações em instituições culturais (em específico os museus, nesse projeto) mostra-se de crescente importância e com grande potencial exploratório para o campo da Ciência da Informação, uma vez que (Roque, 2014b)

As novas tecnologias assumem um papel relevante na remoção de obstáculos ao acesso e ao uso da informação. No caso dos museus, essa função facilitadora permite aproximar o utilizador de objetos únicos, independentemente da sua localização e sem necessidade de intermediação humana direta.

As tímidas iniciativas de aplicação de tecnologias como algo além de meio técnico para possibilitar o acesso e disseminação da informação não são desenvolvidas em todo seu potencial, e uma vez que elas tornam possíveis modelos de mediação jamais pensados antes do seu desenvolvimento, perde-se a oportunidade de criar um novo tipo de experiência e relação entre os usuários e as instituições. Segundo Roque (2014a), "a utilização das novas tecnologias mantém-se como um meio auxiliar: a informação em suporte digital, sem identidade própria, não oferece uma vantagem substancial em relação à informação em suporte analógico". Para tanto, é necessário uma nova posição das instituições diante do espaço crescente da tecnologia na sociedade, e entender que os museus (por mais tradicionais que sejam) não devem deixar de lado as possibilidades que podem ser construídas a partir desse entrosamento.

\section{Metodologia da pesquisa}

Durante a pesquisa foram desenvolvidas atividades visando a encontrar similitudes entre as áreas de Ciência da Informação e Humanidades Digitais, propondo um diálogo entre ambas, além de possíveis práticas conjuntas passíveis de execução e de interesse do profissional da Informação.

As atividades desenvolvidas podem ser divididas, grosso modo, em três momentos principais: 
- Revisão bibliográfica: O intuito com a leitura e discussão dos textos foi de esclarecer conceitos e pensar, inicialmente, em possíveis conexões entre tais áreas do conhecimento, além de base teórica para a elaboração do instrumento de pesquisa utilizado para análise dos sites institucionais.

- Elaboração do instrumento de pesquisa: Após a abordagem teórica, o próximo passo para uma abordagem prática baseou-se na construção de uma ferramenta de avaliação dos objetos a serem tratados, consistindo a mesma de uma ficha de recenseamento de unidades de informação, e sua composição ocorreu ao mesmo tempo que a seleção dos sites institucionais para avaliação. $\mathrm{O}$ objetivo do instrumento construído é avaliar as representações virtuais das unidades de informação e a adequação e oferta de informações e atrativos dos mesmos no suporte digital, assim como a utilização que fazem dos recursos digitais e multimídia como meio de disseminar e facilitar o acesso à informação e à cultura, inspirando-se em Tomael (2008) e em Inafuko e Vidotti (2012).

- Aplicação do instrumento de pesquisa: Após o mapeamento, 24 sites foram escolhidos para serem submetidos à ficha de recenseamento. As avaliações foram aplicadas para análise dos espaços digitais (sites, blogs, acervos virtuais, etc.) relacionados a tais instituições, seguindo o campos da ficha de recenseamento, e preenchidas de acordo com a presença ou ausência de critérios considerados importantes, com espaço aberto para observações diversas.

\section{Resultados}

Foram avaliados 24 sites relacionados a museus e instituições culturais da cidade de Ribeirão Preto, no Estado de São Paulo, Brasil, e região. Em um primeiro momento, os sites foram separados em duas categorias: Estáticos (quando apenas apresentam informações e não possuem recursos interativos, como acesso ao acervo, vídeos, tour online, etc.) e Interativos (quando possuem ao menos um dos itens descritos como interativos na ficha de recenseamento). O resultado da avaliação indicou que, entre as instituições analisadas, é mais comum encontrar sites cuja informação é estática, geralmente com poucas imagens e apenas informações básicas sobre a instituição.

Entre o total de sites estáticos (14), notou-se que mais da metade (9) eram na verdade páginas do site da prefeitura das cidades, e não das próprias instituições. Nesses sites, não foi ob- servado especial cuidado com o design ou usabilidade. Muitas vezes confusos e com links para endereços já desativados, sites desse tipo geralmente apresentam apenas informações básicas como localização, horário de funcionamento e sobre a história e/ou fundação da instituição. Não há muito uso de recursos multimídia como atrativo e nem formas de interação para o usuário.

Em relação aos sites interativos, o principal uso de tecnologia digital observado foi na criação/reprodução de acervo online. Não observamos casos de digitalização de documentos, por exemplo, sendo essa uma das formas de criação de acervo online mais ricas, por permitir a reprodução de um documento histórico no meio digital sem perder seu aspecto físico e tornando-o mais próximo do usuário, uma vez que documentos históricos, por suas características delicadas devido ao passar do tempo e condições de armazenamento a que foram submetidos, raramente são de possível acesso dos usuários. Porém, ainda de maneira tímida e não utilizando todo o seu potencial, mas com acervos de conteúdos diversos, foram encontrados exemplos interessantes de acervos digitais.

Outro fator analisado foi a frequência de atualização dos sites das instituições. Durante a elaboração da ficha de recenseamento foi discutida a importância da constante atualização dos sites, não apenas para que as informações ali fornecidas sejam sempre compatíveis com a realidade (como, por exemplo, divulgação de exposições atuais e futuras), mas também como um meio de atrair usuários para o site, através de divulgação de informações e notícias relativas à esfera cultural da cidade e região.

Notou-se que sites interativos são, em sua maioria, atualizados com maior frequência. Recursos interativos como acervo digital, vídeoaulas e tour online necessitam, por si só, de constante atualização, além de manutenção para garantir que tais recursos estejam sempre em pleno funcionamento. Em relação aos sites estáticos, já foi dito que em sua maioria consistem em páginas no site da prefeitura das cidades, apresentando apenas informações estáticas. Nesses casos, as atualizações das páginas, geralmente, não são frequentes, uma vez que dificilmente um museu mudaria sua instalação física. Nos sites que apresentaram informações sobre as exposições disponíveis, houve tanto casos de informações desatualizadas quanto de informações atualizadas, não sendo observado um padrão específico. 


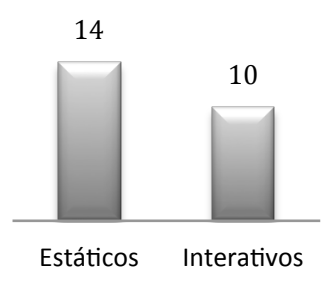

Figura 1. Tipos de site

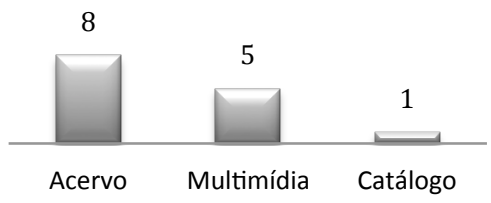

Figura 2. Principais recursos encontrados

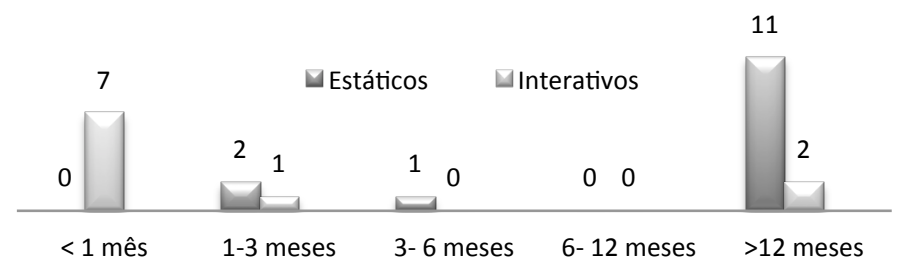

Figura 3. Frequência de atualização

\section{Considerações Finais}

As tímidas iniciativas de aplicação de tecnologias como algo além de meio técnico para possibilitar o acesso e disseminação da informação não são desenvolvidas em todo seu potencial, e uma vez que elas tornam possível modelos de mediação jamais pensados antes do seu desenvolvimento, perde-se a oportunidade de criar um novo tipo de experiência e relação entre os usuários e as instituições. Como já afirmou Roque (2014a), o uso das tecnologias de informação e comunicação cumpre função apenas auxiliar, reproduzindo o padrão da informação analógica sem explorar outras potencialidades, sem identidade própria. Para tanto, é necessário uma nova posição das instituições diante do espaço crescente da tecnologia na sociedade, e entender que as unidades de informação, em particular os museus, não devem deixar de lado as possibilidades que podem ser construídas a partir desse entrosamento. Quanto ao posicionamento dos museus (Roque, 2014a):

A questão é se os museus estão empenhados em integrar-se neste domínio da investigação e assumir a aplicação das novas tecnologias como exercício prioritário, no sentido em que pode ser facilitador das restantes funções museológicas. Em geral, a resposta óbvia é que sim. A forma como alguns museus - sobretudo, os grandes museus, mas também algumas instituições museológicas de menor projeção - tem vindo a propor e a exigir o desenvolvimento de ferramentas e aplicações informáticas é incontestável.

Durante o desenvolvimento da pesquisa foi observado que grandes museus já aderiram às novas tecnologias e fazem uso exemplar de diálogo entre mediação cultural, acessibilidade e tecnologia, sendo exemplos de aplicação das Humanidades Digitais. Entretanto, levar esse conhecimento e possibilidade de implantação a instituições menores ainda parece ser tarefa difícil, mas também um desafio para o profissional da informação, tornando-se uma área emergente para atuação profissional, com a perspectiva de um mercado de trabalho crescente e com grande possibilidade de expansão.

\section{Agradecimentos}

Os autores agradecem à FAPESP e ao CNPq pelos auxílios ao desenvolvimento dessa pesquisa.

\section{Referências}

Galina-Russell, Isabel (2012). Retos para la elaboración de recursos digitales en humanidades. // El profesional de la información. 21:2 (2012, março-abril) 185-189.

Guerreiro, D.; Borbinha, J. (2014). Humanidades Digitais:novos desafios e Oportunidades (novo artigo). // Revista Internacional del Libro, Digitalización y Bibliotecas. 2:2. http://ijbes.cgpublisher.com.

Inafuko, Laura Akie Saito; Vidotti, Silvana Aparecida Borsetti Gregorio (2012). Diretrizes para o desenvolvimento e a avaliação de blogs de biblioteca. // Encontros Bibli: revista eletrônica de biblioteconomia e ciência da informação. 17:35 (dez. 2012) 145-166.

Krebs, Germán (2008). Museos, aprendizajes y tecnologías de la información y la comunicación. // Decysio. 20 (Mayo- Agosto, 2008). http://www.crefal.edu.mx/decisio/ima ges/pdf/decisio_20/decisio20_saber5.pdf>

Lévy, Pierre (1999). Cibercultura. São Paulo, 34, 1999.

Portela, Manuel (20113). Humanidades digitais: as humanidades na era da web 2.0. // Rua Larga. 38 (dezembro 2013). http://hdl.handle.net/10316.2/26328.

Roque, Maria Isabel (2014a). Humanidades Digitais para os museus. 11/Abr//2014. http://amusearte.hypotheses.org/373.

Roque, Maria Isabel (2014b). Persistência e mudança: a difícil adesão dos museus às Humanidades Digitais. 15/Out/2014. http://amusearte.hypotheses.org/724.

Rodriguez Yunta, Luis (2013). Las humanidades digitales, ¿una mera etiqueta o un campo por el que deben apostar las ciencias de la documentación? // Anuario ThinkEPI 2013. http://digital.csic.es/bitstream/10261/77511/ 1/037-043-Rz-Yunta-Humanidades-digitales.pdf.

Svensson, Patrik (2010). The Landscape of Digital Humanities. // Digital Humanities Quarterly. 4:1.

Tomaél, Maria Inês et. al. (2008). Fontes de informação na internet: critérios de qualidade. // Tomaél, Maria Inês (Org.). Fontes de informação na internet. Londrina: EDUEL, 2008.

Enviado: 2015-04-01. Segunda versión: 2015-06-24. Aceptado: 2013-09-01. 